\title{
AS PINTURAS DO "MUSEU DE ARTE PRIMITIVA DE ASSIS - JOSÉ NAZZARENO MIMESI": MOSAICO ICONOGRÁFICO DA ARTE SUBALTERNA BRASILEIRA
}

\author{
Prof. ${ }^{a}$ Ms. Kátia Maria Roberto de Oliveira Kodama \\ Doutoranda em Ciências da Comunicação-ECA-USP.
}

Para uma reflexão acerca das manifestações culturais pertencentes às culturas subalternas, nas suas relações com conteúdos de ordem ideológica numa sociedade historicamente dada, foi selecionado como objeto de pesquisa o folguedo Folia de Reis, que ocorrem no bairro rural de Ribeirão Grande em Ourinhos/SP e cidades vizinhas e está representado em várias obras do acervo do "Museu de Arte Primitiva de Assis Nazareno Mimessi". A cidade de Assis, localizada na região, abriga o museu de arte acima citado que leva o nome de seu fundador - Nazareno Mimessi - mineiro de Caxambu. Corretor de seguros e imóveis, poeta e autodidata, tornou-se um grande colecionador e pesquisador da Pintura Popular, doou obras de seu acervo para articular seu início. Hoje o Museu pertence à Fundação Assisense de Cultura "Joshey Leão", sua estrutura compõe-se de três salas, duas para exposições temporárias e uma permanente com obras de seu acervo.

As pinturas e os objetos do acervo são fontes iconográficas que descrevem as danças, instrumentos musicais, formas de devoção, paisagem, arquitetura, costumes e as organizações sociais, explicitam valores estéticos, simbólicos e didascálicos, onde se vislumbram as origens transregional e pluricultural que distinguem a formação dos modos viventes do Sudoeste Paulista.

O interesse em compreender as manifestações iconográficas produzidas nas culturas subalternas se faz necessário para avaliar como se constituem, sobrevivem, processam e recriam-se suas formas comunicacionais e estéticas, também representante da cultura do Brasil para estabelecer um referencial teórico que subsidie o entendimento da dinâmica da sociedade atual. Igualmente é preciso depreender esforços no sentido de registrar e documentar as manifestações portadoras do ideário e tradições que remontam a formação da cultura brasileira presentes nas obras do Museu, detentor de um acervo de 1.300 peças.

Nesta ótica as representações imagéticas do museu cumprem dupla função - auxiliar na compreensão e resgate das práticas ritualísticas e 
simbólicas da festa - e propiciar um debate sobre as inúmeras conceituações empregadas para compreender o gênero de pinturas de seu acervo.

Da mesma forma, a escolha do tema FESTA como objeto de pesquisa justifica-se pela perspectiva de ser está - uma manifestação cultural - capaz de explicitar a gênese de uma comunidade; em seus estudos Ferreira, tece considerações a este respeito: "A festa reproduz simbolicamente a condição do caos mítico primordial, quando a promove a anulação do presente. Assim, a festa é um simbólico retorno às origens - uma origem muitas vezes imaginária on reinterpretada - necessário para garantir a integridade do individuo", (FERREIRA; 2005; p.75). Além disso, é possível ver nas festas uma profunda simbiose com as culturas ou "categoria da cultura", através de dois aspectos importantes:

"O primeiro deles é a capacidade que a festa tem de trazer para a atualidade, desde longínquas épocas, as experiências culturais vivenciadas por determinada população; o segundo aspecto refere-se ao fato de que, mesmo contrariando as práticas intencionalmente concebidas no momento da festa, os usos e costumes mais profundos vivenciados pela cotidianidade e entranhados no inconsciente afloram, mostrando a verdadeira face de um povo, moldada através da cultura".( Ferreira; 2005;p 72).

Nos bairros e cidades visitadas as festas religiosas que se destacam são, Festa do Divino, Congada e a Folia de Reis, sendo esta ultima, o folguedo que aglutina e mobiliza de 5 a 15 mil pessoas, número de participantes muito significativos em relação a seus habitantes que variam entre 3.000 a 105.000 . Neles foram observados suas características estéticas e simbólicas, suas possíveis descaracterizações e os processos de assimilação e acomodação de novas informações.

Estudar, portanto, as manifestações das culturas subalternas promovidas pelos diferentes grupos, é uma forma de conhecer os mecanismos e os veículos comunicacionais que permitem a conservação, adaptação, transmutação e sobrevivência de tradições que sustentam a cultura do país e região; bem como, de buscar informações nas próprias comunidades da melhor forma de preservá-las, frente as constantes influências dos meios massivos de comunicação que provocam fortes rupturas nos seus modos de ser e vivenciar o cotidiano.

Desta forma as manifestações plásticas do museu formam um mosaico iconográfico da cultua subalterna, Ortiz "diria que a consciência popular opera por bricolagem, ao contrário da cultura burguesa, que é global e unitária”.(Ortiz;1985;p.45). Esta idéia estrutura a base que constitui a gênese da formação e do desenvolvimento cultural da região, que impõe, por conseguinte, a necessidade da utilização de uma fundamentação teórica que 
contemple toda a riqueza e diversidade cultural encontrada nas festas registradas.

Para abarcar essa dinâmica de multiculturas em coexistência no país e na América Latina far-se-á uso do termo de origem gramsciana de cultura subalterna ou cultura das classes subalternas. Ortiz infere, ainda, "O pensador italiano Antônio Gramsci, ao criar esta expressão, empregava-a no sentido de diferenciar patrimônio cultural do povo da cultura oficial", (Ortiz; 1985; p.47). Denominada também por este mesmo autor em suas obras de cultura dominante, cultura das classes dominantes ou hegemônicas.

As culturas subalternas guardam tradições que se articulam com a estrutura psico-social das populações e tornam-se importantes para explicar e fundamentar o conceito de cultura nacional:

“os rituais e costumes do passado não são somente soluções úteis ou meras expressões conservadoras. Seu sentido vai mais longe e se mostra mais nítido quando se descobre neles formas de resistir aos efeitos deformadores da cultura dominante. Nestas manifestações, encontram-se soluções para o presente. Não se trata de conservadorismo, mas, em muitos casos, de preservação de uma base a partir da qual, resistir significa conservar a identidade, a dignidade e a solidariedade." (Maguiles; 1991; p. 62)

Nos estudos imagéticos do Museu, fez-se necessário recorrer ao pensamento gramsciano, como forma de racionalizar e embasar teoricamente uma área de pesquisa carente de debates e conceituações, devido ao amplo leque de definições encontradas em diferentes fontes nem sempre confluentes ou complementares quando se trata das pinturas aqui mencionadas e congêneres do país.

Mimessi em suas pesquisas explicita a diversidade dos termos que encontrou para designar as manifestações plásticas reunidas no museu em sua "árvore genealógica das denominações da Pintura Primitiva". Elenca 47 designações, destacando-se:

"Pintores do Coração Sagrado, Pintores do Instinto e do Coração, Pintores Mestres da Realidade Popular, Pintores Puros, Pintores Intuitivos, Pintores Kitsch, Pintores Populares, Pintores Populistas, Pintores Sem Estudo, Pintores Domingueiros, Pintores Caipiras, Pintores Não Educados, Pintores do Imediato, Pintores Democráticos, Pintores Improvisadores, Pintores da Semana dos Sete Domingos..." MIMESSI; 1991; p1)

Rossini Tavares de Lima e Julieta de Andrade, também recorreram a diferentes classificações como: arte folclórica, artesanato folclórico, e fizeram uso ainda dos conceitos de cultura letrada, para cultura erudita e pré-letrada, arte folclórica, popularesca e primitivista, também chamada por eles de neoprimitiva, ingênua e ínsita (do latim insitos, inato). 
Em sua tese de doutorado sobre a dimensão econômica da arte e da pintura, Pinho (1998) também recorre a diferentes conceitos para analisar o mercado de arte e a importância dada pelos consumidores ao que denomina de arte ingênua, ou arte naive (art naïf), kitsch e art brut . A autora cita ainda os pintores que reproduzem um padrão estético muito próximo dos artistas oriundos das camadas subalternas, aqueles que trabalham de modo artesanal, chegando muitas vezes à escala industrial para a venda de quadros a grandes lojas, reproduzindo o mesmo tema centenas de vezes, ou os que fazem quadros heterogêneos e ecléticos, baseando-se em cópias para o grande público e feiras de arte-artesanato.

O pesquisador de arte sacra popular, Eduardo Etzel (1992), referese a estas produções como arte ingênua, arte primitiva, primitivo moderno, neoprimitivismo, arte popular, arte popularesca e arte folclórica.

Nesta perspectiva, as contribuições das Ciências Sociais ainda são recentes, mesmo após os caminhos abertos pós-Semana de 22, que implementaram novos estudos que se apropriaram das manifestações das camadas subalternas para dar suporte e uma identidade ao que se propunha, e, de tal modo, desvendar a gênese da cultura brasileira.

Mário de Andrade apud Avancini (1992) reuniu, no conjunto dos vinte volumes que compõem suas Obras Completas, nove relacionado a críticas das artes, procurou manter sempre uma unidade de propósito na busca de conceitos de uma arte brasileira, sua origem e uma constante "busca das fontes populares e folclóricas que alimentavam e enriqueciam a arte culta e moderna produzida pelos modernistas" (AVANCINI; 1992; p. 93), elaborou uma crítica seletiva, fundamentada na história, para justificar a produção de sua época e a delimitação de seu caráter nacionalista, reescreveu seus conceitos, utilizando diferentes e variadas abordagens para explicar o fenômeno e o objeto artístico.

Bem como, Roger Bastide apud Silva(1991), outro pós modernista procurou uma nova visão das manifestações estéticas da cultura do povo brasileiro elaborando uma denominada "Teoria das Mutações", subsídio conceitual que não se manifestou, mas está presente em seus textos; não tinha por meta enquadrar seus estudos na sociologia, antropologia ou psicologia social, apaixonara-se pela criatividade, procurava na sociologia o alicerce do fazer artístico, utilizando as ciências que precisasse, via as artes como a vida do outro.Queria penetrar nas idéias do outro, ouvi-lo, e compreender seu percurso intelectual, desta forma, contribuiu muito para criar uma nova visão de cultura brasileira. 
Da mesma forma,estudiosos fora do Brasil também procuraram definir as produções populares, Hauser (1958), constrói seus argumentos sempre comparando as manifestações artísticas e culturais, como se fossem compartimentos isolados em oposição permanente, "arte folclórica significa as atividades poéticas, musicais e pictóricas dos estratos da população que não são cultos nem urbanizados on industrializados".(Hauser; 1958; p. 243). A linha de pensamento de Hauser está muito distante da realidade atual onde as culturas transitam em todas as esferas e o espaço rural e urbano foram diluídos.

Nesse sentido, o pensamento de Gramsci apud Lajolo(1920) tornase mais apropriado, quando explicita o subalterno como um conceito policlassista que se adapta e cria outros significados nos movimentos do sistema através de seus próprios meios de comunicação. Sob este prisma, no mundo globalizado, a compreensão das culturas subalternas possibilita abarcar a identidade cultural e a construção simbólica do país e dar sentido às representações imagéticas a elas pertencentes.

Mesmo assim, Gramsci é, por certo, através do conceito de cultura subalterna, o pensador que mais atende à necessidade de não hierarquizar ou usar artifícios de classificação dicotômicos em se tratando das manifestações artísticas/culturais, mas seu pensamento não esgota todas as respostas. Deste modo, o desafio que emerge é: como compor um quadro teórico que utilize os princípios gramscianos de culturas de classe subalternas e hegemônicas com a realidade caótica de nossa contemporaneidade?

Conjetura-se ampliar esta reflexão nos textos de Santaella (2004) que apresenta uma divisão da cultura em seis eras: a da cultura oral, escrita, impressa, de massa, das mídias e a digital. A autora esclarece ainda, que a cultura das mídias não pode ser confundida como cultura de massa e nem como cultura digital, situa-se como uma cultura intermediária, também considera que as "seis eras" não podem ser vistas como processos lineares "como se uma era fosse desaparecendo com o surgimento da próxima. Ao contrário, bá sempre um processo cumulativo de complexificação: uma nova formação comunicativa e cultural vai se integrando na anterior, provocando nela reajustamentos $e$ refuncionalizações." (SANTAELLA; 2004; p. 13).

Nesse processo, ciências como história, filosofia, psicanálise, comunicação e semiótica e, sobretudo, a arte, explicam melhor o turbilhão de vivências em que a humanidade está mergulhada na atualidade, principalmente as manifestações imagéticas: 


\begin{abstract}
“Na abertura de seu texto 'A Casa dos Espelhos' (1997) Norman T. White diz que, para ele, 'a arte torna-se viva somente quando ela oferece uma estrutura teórica para questionamentos. A ciência oferece essa estrutura teórica também, mas, para mim', continua White, 'a "boa-ciência" é por demais restritiva. Eu preferiria fazer perguntas que se endereçassem simultaneamente a múltiplos mundos - dos organismos vivos até a cultura, a ferrugem e ao caos. Somente a arte me dá essa generalidade'." (SANTAELLA; 2004; p.26)
\end{abstract}

Para a autora, a arte é o veículo comunicacional que está impregnado de síntese do presente, mas apontando para o futuro, pois encontra-se sempre próximo dos "enigmas do real", afirma ainda que, nos tempos mutantes da atualidade, os artistas fornecem as explicações mais imediatas "pelo simples fato de que, parafraseando Lacan, eles sabem sem saber que sabem". As considerações de Santaella assinalam desse modo, para a pluralidade de conceitos e áreas de conhecimento na tentativa de compreender as manifestações imagéticas que convivem na sociedade das "Eras Culturais".

A dinâmica de coexistência de diferentes culturas é um fenômeno que se tornou visível na contemporaneidade. Os processos midiáticos interligaram não só diferentes culturas de um mesmo país, como introduziram significações e termos utilizados em culturas distantes, antigas, tornando-as ativas no tempo presente. Em nosso processo histórico e contemporâneo inúmeras vezes o oriente e o ocidente se cruzaram, desses encontros, resultam uma absorção de termos e conceitos que se perdem de sua origem.

Atualmente o termo avatar está sendo utilizado pelos meios midiáticos - principalmente os digitais - quando é preciso descrever um personagem ou a própria pessoa em uma realidade virtual, agregando em uma dada situação vivida ao mesmo tempo virtualmente e no real, um conjunto de expressões, atitudes, sentimentos, condutas, vivências e objetos simbólicos que compõem um mosaico comportamental, visual; dando assim ao personagem sentimentos, características psicológicas e atitudes próprias de seu criador, o personagem age ao mesmo tempo como seu criador ou vice-versa - a essência de suas atitudes são uma só - não é possível o criador se distanciar de sua criação, existe ali um segundo eu agindo ao mesmo tempo em uma realidade virtual e real. A palavra avatar é descrita em dicionários como tendo sua origem no sânscrito Avatara que significa descida, normalmente denotando uma das encarnações (religião) de Vishnu (deus hindu). Pode ser também uma manifestação corporal de um ser imortal, por vezes até do Ser Supremo, além de significar transformação, transfiguração, metamorfose. 
Nas Festas observadas registrou-se a utilização dos meios de comunicação de massa para sua divulgação, assim como, a utilização dos avanços tecnológicos incorporados durante sua realização, na contratação de empresas especializadas em eventos que fornecem barracas, tendas, palco, som, na terceirização e industrialização das comidas servidas, no seu uso político, no potencial econômico que geram.

Mas sua essência continua como um "avatar" - existe ali um segundo eu agindo ao mesmo tempo - que preserva os elementos de origem que remontam às denominadas epifanias, para os desavisados, a primeira leitura das festas pesquisadas, faz pensar que as manifestações atuais perderam sua essência, mas nelas estão incluídos os festejos pela passagem bíblica que relata a visita dos três Reis Magos ao filho de Deus dentro das festas do ciclo natalino - uma simbiose entre o sagrado e profano - que dão um sentido transcendental para as comunidades que as realizam. A festa do bairro de Ribeirão Grande em Ourinhos/SP. acontece em fins de junho ou de início julho, portanto, tradicionalmente dentro do ciclo comemorativo junino. Em suas origens não havia data específica para essas comemorações que aconteciam em diferentes momentos. A unificação do calendário cristão foi feito pelo Papa Julio I, em 367 d.C. que fixou a data de 25 de dezembro para a festa do nascimento de Cristo e dia 6 de janeiro para celebração e adoração dos Reis Magros. Portanto, a Folia de Reis é composta de procissões e cortejos que representam a viagem dos Reis Magos vindos do Oriente em busca do Menino Jesus. Essa tradição foi trazida pelos portugueses onde era comum dar e receber presentes entoando cantos e danças ou apenas pedindo esmola e alimentos. No Brasil $\mathrm{a}$ área de maior incidência tem sido a região Sudeste. $\mathrm{O}$ dia de Reis marca oficialmente o fim do ciclo natalino com uma grande comemoração onde as prendas arrecadadas durante a peregrinação são distribuídas para a comunidade. Os grupos de foliões são compostos geralmente por três homens mascarados representando os magos, um ou mais palhaços relacionados a Herodes e soldados. Seguem esses personagens um mestre, tocadores, cantores e porta-bandeira.

Uma das exigências para participar de uma folia é que o folião deve permanecer nela por sete anos seguidos, sob pena de receber castigos. Após esse período, o devoto pode tornar-se mestre ou estar livre da obrigação com o grupo. A participação das folias é motivada pela paga de promessas ou para fazer pedidos ao menino Jesus. Normalmente não é permitida a presença de mulheres. As folias fazem peregrinação geralmente à noite, indo nas casas dos devotos, que se sentem abençoados pela visita da 
bandeira e orações. Ao chegarem entoam cantos de saudação aos donos da casa e em louvor a Jesus Cristo, pedindo proteção e bênção. Após o ato sagrado, realizam uma apresentação de danças profanas.

Há diferentes indumentárias para os grupos. As músicas têm como base de suas letras os acontecimentos da natividade descritos no Novo Testamento. Estas características básicas são mantidas em todas as festas pesquisadas, sendo incorporadas em cada uma, releituras próprias de cada cidade ou bairro. O mesmo acontece com as representações imágeticas estudadas no museu. Elas explicitam visualmente as tradições e as novas adaptações sofridas, tornam-se documentos incontestáveis dos fatos reais e fornecem pistas para desvendar o presente através dos símbolos e signos visuais que se repetem .

Portanto, seja pela representação do aspecto do sagrado, seja pela incorporação de elementos do presente, cada festa está incorporada na realidade das "eras culturais" convivendo concomitantemente com suas origens sacro-profanas, tornando-se um "avatar" de sua comunidade.

\section{Bibliografia}

AVANCINI, José Augusto. Arte e Cultura da América Latina. Ano II, no 3 - Setembro, 1992. São Paulo: Sociedade Científica de Estudos da Arte - CESA.

FERREIRA, Maria Nazareth (Org.). Cultura subalterna e neoliberalismo: a encruzilhada da américa latina. São Paulo: CELACC: ECA/USP, 1997.

e Colaboradores. Globalização e identidade cultural na América Latina (a cultura subalterna frente ao neoliberalismo). São Paulo: CEBELA, 1995.

HAUSER, Arnold. Teorias da Arte. Lisboa: Editora Presença, $2^{a}$ ed., 1998.

LAJOLO, Laura. Antonio Gramsci: uma vida. Editora Brasiliense, 1982.

MADRÍZ, Maria Fernanda. La Cultura Popular en Gramsci, Caracas, Anuário ININCO, nº 2, 1989, UCV. in FERREIRA, Maria Nazareth. Cultura Subalterna e o Neoliberalismo: a encruzilhada da América Latina. São Paulo: CELAC: ECA/USP, 1997.

MAGUILES, Mario. "La cultura Popular", em Adolfo Colombes, La Cultura Popular, México, Premiá, 1991, p. 62.

MIMESSI,José Nazareno. Pintura Primitiva: Naive.Assis:[s.n.], 1991.

ORTIZ, Renato. Cultura Popular: Românticos e Folcloristas. São Paulo: Olho D água, 1985.

PINHO, Diva Benevides. A Arte como Investimento. A dimensão econômica da pintura. São Paulo: Nobel/EDUSP, 1988.

SANTAELLA, Lúcia. Culturas e Artes do Pós-Humano: Da cultura das mídias à ciber-cultura. São Paulo: Paulus, 2004.

SILVA, Dilma de Melo. Arte e Cultura da América Latina. Ano II, no 2 - Julho, 1991. São Paulo: Sociedade Científica de Estudos da Arte - CESA. 